Article

\title{
Two-Tier Reactive Power and Voltage Control Strategy Based on ARMA Renewable Power Forecasting Models
}

\author{
Jinling Lu ${ }^{1}$, Bo Wang ${ }^{2}$, Hui Ren ${ }^{1}$, Daqian Zhao ${ }^{1}$, Fei Wang ${ }^{1,3, *}$, Miadreza Shafie-khah ${ }^{4}$ (D) and \\ João P. S. Catalão ${ }^{4,5,6, *}$ \\ 1 State Key Laboratory of Alternate Electrical Power System with Renewable Energy Sources, \\ North China Electric Power University, Baoding 071003, China; lujinling@126.com (J.L.); \\ dahui.ren@gmail.com (H.R.); cdzq444444@163.com (D.Z.) \\ 2 State Key Laboratory of Operation and Control of Renewable Energy \& Storage Systems, \\ China Electric Power Research Institute, Beijing 100192, China; wangbo@epri.sgcc.com.cn \\ 3 Department of Electrical and Computer Engineering, University of Illinois at Urbana-Champaign, \\ Urbana, IL 61801, USA \\ 4 C-MAST, University of Beira Interior, 6201-001 Covilhã, Portugal; miadreza@gmail.com \\ 5 INESC TEC and the Faculty of Engineering of the University of Porto, 4200-465 Porto, Portugal \\ 6 INESC-ID, Instituto Superior Técnico, University of Lisbon, 1049-001 Lisbon, Portugal \\ * Correspondence: feiwang@ncepu.edu.cn (F.W.); catalao@ubi.pt (J.P.S.C.)
}

Received: 31 July 2017; Accepted: 26 September 2017; Published: 1 October 2017

\begin{abstract}
To address the static voltage stability issue and suppress the voltage fluctuation caused by the increasing integration of wind farms and solar photovoltaic (PV) power plants, a two-tier reactive power and voltage control strategy based on ARMA power forecasting models for wind and solar plants is proposed in this paper. Firstly, ARMA models are established to forecast the output of wind farms and solar PV plants. Secondly, the discrete equipment is pre-regulated based on the single-step prediction information from ARMA forecasting models according to the optimization result. Thirdly, a multi-objective optimization model is presented and solved by particle swarm optimization (PSO) according to the measured data and the proposed static voltage stability index. Finally, the IEEE14 bus system including a wind farm and solar PV plant is utilized to test the effectiveness of the proposed strategy. The results show that the proposed strategy can suppress voltage fluctuation and improve the static voltage stability under the condition of high penetration of renewables including wind and solar power.
\end{abstract}

Keywords: ARMA; reactive power; voltage stability; control strategy; renewable

\section{Introduction}

In recent years, with the rapid development of renewable generations, the scale of the integration of wind power and solar power stations increase rapidly [1,2]. In China, wind farms and solar PV power stations are mainly located in the north and northwest regions, while load-centers are located far away in eastern regions. As the increase of the integration, the influence of the randomness at the generation side and long-distance transmission on voltage stability is more and more prominent [3-5].

Many papers studied the voltage and reactive power control strategy at the turbine level, wind farm level, and wind farm group level [6-17]. In order to participate in voltage regulation, a wind turbine can increase its reactive power output to some extent by lowering its active power output [6]. The performance of alternative voltage control strategies applied to a doubly-fed induction generator (DFIG) are explored and compared [7]. Stator- and grid-side converters could be adjusted for voltage-control purposes. Different control sequences will lead to different control performance [8]. 
The main concern of the dispatching of the system is voltage and reactive power at the PCC (point of common coupling). Therefore, a centralized controller is needed in the wind farm to monitor and maintain the voltage at the interconnection nodes. Wind turbines are used as the second voltage controller to provide satisfactory reactive power and voltage control effects when there was communication delay in the centralized controller of wind farm [9]. The coordinated control of conventional VAR compensation devices, wind farm or PV stations, and dynamic devices can further improve the voltage and reactive power control performance of the system [10-12]. A transient voltage stability scheme integrated with passive SFCL (superconducting fault current limiter) and active TVC (transient voltage control) voltage compensators for the DFIG-based wind farm was proposed in [10]. With coordinated control of the turbine and reactive power compensation equipment in the wind farm, the network voltage profile is improved and the voltage stability is enhanced [11,12]. Due to the centralized location and high output correlation, the wind farm group has greater influence on voltage stability. A two-stage voltage control model of the wind farm group considering main transformer tap adjustment was proposed in [13]. The three-layer automatic voltage control strategy of wind farm group is studied, which takes the voltage deviation and voltage stability as the optimization objectives [14]. Compared with wind power, the output of photovoltaic power is less random, but as its generation does not involve mechanical components, the PV output may fluctuate rapidly and dramatically. It has been proved in [16] that through reactive power control, voltage magnitude fluctuations due to short-term PV power variability can be mitigated. High penetration of PVs in the distribution network can result in overvoltage in some operating conditions. Reactive power control algorithms are proposed to maximize the PV generation and guarantee the voltages of all buses in the acceptable range [15]. Local adaptive active power curtailment of PV systems for overvoltage suppression was considered as well. A reactive power and voltage coordinated control strategy for a grid-connected wind-PV hybrid system was proposed in [17].

The above reactive power and voltage control strategies did not consider the operating characteristics of commonly-used reactive power compensation devices, such as shunt capacitors, in the system and the voltage stability margin problem. On one hand, shunt capacitors cannot be adjusted smoothly and quickly. A time delay is needed for the voltage to be regulated to meet the requirements. On the other hand, the wind farm and PV power plants are normally far away from the load-center, and electricity needs to be transmitted through long-distance lines. Ignoring the static voltage stability margin will be detrimental to the stable operation of the system.

Considering the operating characteristics of reactive power compensation devices and the voltage stability margin, a two-tier reactive power and voltage control strategy is proposed in this paper to solve the abovementioned problems. Based on the single-step predicted output of wind and solar power by the autoregressive moving average (ARMA) time series forecasting models, the voltage at selected substations are regulated through regulating shunt capacitor devices. The objective of the first-tier strategy is to minimize the voltage deviation at these central points. Due to the errors between the actual output and the forecasted output of the wind farm and the solar power station, and the limitation on the control flexibility of shunt capacitors, the predefined objective for period $t$ (voltages at selected central points for the next control period, for example, next $15 \mathrm{~min})$ designed at period $(t-1)$ in the first-tier strategy may not be met at period $t$. Therefore, at the target control period (period $t$ ), the static voltage compensators, and the reactive output of wind farm and solar stations are regulated to mitigate the voltage variation of central points between period $t$ and the predefined objective given at period $(t-1)$ by the first-tier strategy to improve the stability margin and the dynamic reactive power margin. The reactive power output of shunt capacitors, wind farm, photovoltaic station, and the dynamic reactive power compensation devices are optimized through the particle swarm optimization (PSO) algorithm, and coordinated by two-tier strategies. 


\section{ARMA-Based Power Forecasting Model}

Instead of mitigating the influence of variable renewables through the curtailments from the demand side [18], wind and solar power forecasting are still the most effective means of handling the uncertainty of renewable power generation. Several different models have been successfully applied to the forecasting of renewable power generation in terms of wind power [19-23] and solar power [24-26]. In this paper, the ARMA time series model is applied to establish the forecasting model based on historical data [21]. ARMA forecasting is simple and fast, suitable for the pre-control of discrete equipment. The forecasting can be performed through three steps, including system modelling, parameter estimation, and adequacy validation. It has been applied to the research of wind power prediction successfully.

In the time series modeling, we need to smooth the observation data sequence so that the non-stationary data sequence can be transformed into a stationary random sequence with zero mean.

The mean value of time series $\left\{x_{t}\right\}$ with finite length $N$ is calculated by the following:

$$
\begin{gathered}
\mu_{x}=\left(\sum_{t=1}^{N} x_{t}\right) / N \\
y_{t}=x_{t}-\mu_{x}(t=1,2, \cdots, N)
\end{gathered}
$$

Thus, the zero mean time series $\left\{y_{t}\right\}$ is obtained.

The general ARMA model can be described as follows [27]:

$$
y_{t}=\sum_{i=1}^{p} \alpha_{i} y_{t-i}+\varepsilon_{t}-\sum_{j=1}^{q} \beta_{j} \varepsilon_{t-j}
$$

where $p, q$ are the orders of the ARMA model, $\alpha_{i}$ and $\beta_{j}$ are parameters of the ARMA model, $\varepsilon_{t}$ is stationary white noise with zero mean.

Equation (3) shows that the AR model, the autoregressive process, describes the system's memory of its past state; the MA model, the moving average process, describes the system memory of the previous noise (random disturbance term) into the system. Therefore, the ARMA model is the system memory of its own states and the past noise into the system. $y_{t}$, the value of a time series ARMA $(p, q)$ at moment $t$ can be represented by a linear combination of $p$ historical observations plus a moving average of the $q$ term of a white noise sequence. Please see [27] for the detailed steps of the identification process of the model.

\section{Two-Tier Reactive Power and Voltage Control Strategy}

Currently, the reactive power regulation devices in wind farms and solar power plants are mainly shunt capacitors and dynamic reactive power compensation devices. The output of reactive power of shunt capacitors has two features: (1) the output of each unit is discrete; (2) the switching operation time is relatively long compared to the variation of the reactive power. When the output power of the solar PV station or wind farm changes dramatically, it is quite difficult to achieve fine voltage regulation only through those shunt capacitors. A static VAR compensator (SVC) and other dynamic reactive power compensation devices are able to provide a continuous, fast reactive power regulation, which can change the reactive power rapidly and stabilize voltage fluctuations quickly.

A two-tier reactive power and voltage control strategy based on the ARMA time series model is put forward, which considers the characteristics of reactive power regulation devices. The control strategy of the first tier is to regulate the discrete equipment based on the single-step prediction information of the wind farm and solar PV power station. This tier aims at minimizing the voltage deviation at the central point. The control strategy of the second tier is to regulate the reactive power output of the SVC, wind farm, and PV power plant based on the real-time measurement. The objective 
of this tier is to suppress the voltage fluctuation of the central point (selected nodes to provide voltage support in power system) and improve the voltage stability margin and the reactive power margin of dynamic reactive power compensation equipment. The second tier control is implemented based on the first tier control. Since the action time of the shunt capacitors is long, the shunt capacitors are regulated in advance based on the forecasted output of wind farms and solar stations. The output of capacitors decided in the previous period ( $15 \mathrm{~min}$ before), as well as the real-time measurement, are used as the input of the second tier optimization to decide the reactive power output of the SVC, wind farm, and PV power plant. The overall reactive power and voltage control strategy is given in Figure 1.

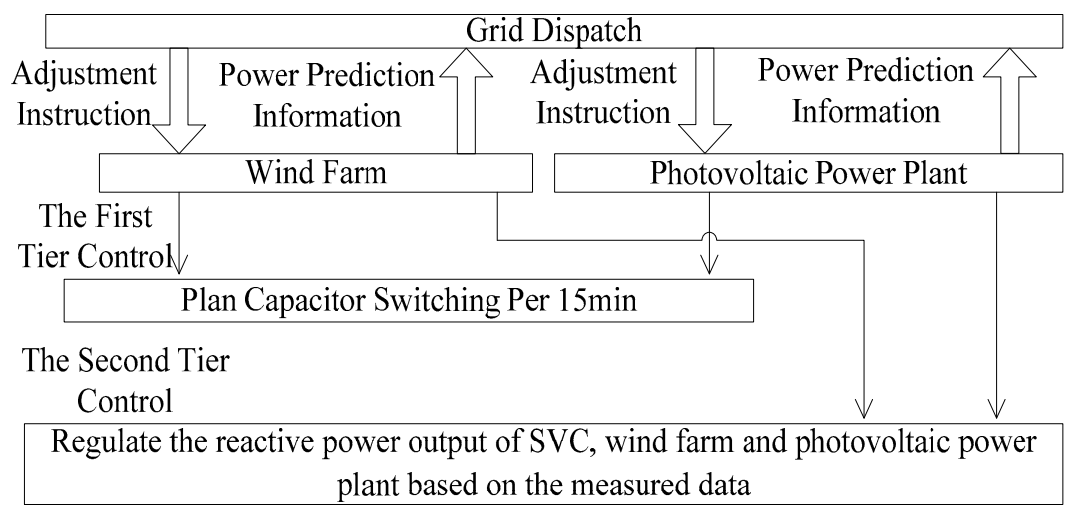

Figure 1. The overall reactive power and voltage control strategy.

\subsection{The First Tier Control Strategy}

The objective function of the first tier control strategy is to minimize the voltage deviation in every control period. We regulate the discrete equipment based on the single-step prediction information of the wind power and PV power station. The high voltage side buses in boost substations of the wind farm and PV power plant are selected as central points in this paper. The objective function is as follows:

$$
\min f_{1}=\Delta U_{1}=\sum_{i=1}^{N}\left(U_{i}^{\mathrm{pr}}-U_{i r e f}\right)^{2},
$$

where $N$ is the number of central points; $U_{i}^{\mathrm{pr}}$ is the predicted value of voltage at central point $i$, and $U_{\text {iref }}$ is the reference voltage at central point $i$.

\subsection{The Second Tier Control Strategy}

The second tier control strategy is to regulate the reactive power output of the SVC, wind farm, and PV power plant based on the real-time measurement. The objective of this tier is to suppress the voltage fluctuation at the central point and to improve voltage stability margin and the reactive power margin of the dynamic reactive power compensation equipment.

\subsubsection{The Index of Voltage Deviation}

Firstly, the reactive power and voltage control strategy should ensure the voltage level of the central point to meet system requirements. The index of voltage deviation is as follows:

$$
\Delta U_{2}=\sum_{i=1}^{N}\left(U_{i}-U_{i r e f}\right)^{2}
$$

where $N$ is the number of central points; $U_{i}$ is the voltage at the central point $i$, and $U_{\text {iref }}$ is the reference voltage. 


\subsubsection{The Index of the Voltage Stability Margin}

The index of voltage stability is calculated based on power flow equations, which is widely used in the identification of the weak point in power system. The $L$ index is calculated through Equation (6). Relations between the voltage stability and the $L$ index is: $L>1$, the voltage is instable; $L=1$, it is in a critical state; and $L<1$, the voltage is stable [28].

$$
L_{i}=\left|1-\frac{F_{i} \cdot U_{\mathrm{S}}}{U_{\mathrm{D}_{i}}} \angle \delta_{i}-\theta_{i}\right|
$$

where $U_{\mathrm{S}}$ is the voltage of equivalent large grid, $U_{\mathrm{D}_{i}}$ is the voltage of node $i$ in the wind and PV centralized system, $F_{i}$ and $\delta_{i}$ are the amplitude and phase of the $i$ elements of the matrix $F$, and $\theta_{i}$ is the voltage phase value of the node $i$ relative to slack bus. The node network equation of the wind and PV centralized system is as follows:

$$
\left[\begin{array}{c}
I_{\mathrm{S}} \\
I_{\mathrm{D}}
\end{array}\right]=\left[\begin{array}{cc}
Y_{\mathrm{SS}} & Y_{\mathrm{SD}} \\
Y_{\mathrm{DS}} & Y_{\mathrm{DD}}
\end{array}\right]\left[\begin{array}{l}
U_{\mathrm{S}} \\
U_{\mathrm{D}}
\end{array}\right]
$$

where $I_{\mathrm{S}}$ and $U_{\mathrm{S}}$ is a matrix consisting of the current and voltage vectors of an equivalently large grid, $I_{\mathrm{D}}$ and $U_{\mathrm{D}}$ is a matrix consisting of the current and voltage vectors of wind and PV connection nodes, $Y_{\mathrm{SS}}, Y_{\mathrm{SD}}, Y_{\mathrm{DS}}$, and $Y_{\mathrm{DD}}$ are the sub-matrices of the node admittance matrix $Y$. The matrix $F$ is calculated as follows:

$$
F=-Y_{\mathrm{DD}}^{-1} Y_{\mathrm{DS}}
$$

Here, the index of the voltage stability margin, $L_{p w}$, is introduced. It is calculated as follows:

$$
L_{p w}=\sum_{i=1}^{N} L_{i}^{2}
$$

where $N$ is the number of central points, and $L_{i}$ is the index of local voltage stability of central point $i$.

\subsubsection{The Reactive Power Margin of the Dynamic Reactive Power Compensation Equipment}

Improving the reactive power margin of dynamic reactive power compensation device can suppress voltage increases at the moment of clearing the fault. The reactive power margin is calculated by Equation (10):

$$
\Delta Q_{S}=\sum_{i=1}^{N_{Q}}\left(\frac{Q_{S i}}{Q_{\text {Simax }}-Q_{\text {Simin }}}\right)^{2}
$$

where $i$ is the node where dynamic reactive power compensation device is installed; $N_{Q}$ is the number of the dynamic reactive power compensation devices; $Q_{S i}$ is the reactive power output at node $i$; $Q_{S i \max }$ and $Q_{S i m i n}$ are the limits of reactive power output.

\subsubsection{The Objective Function}

The objective of second tier is to suppress the central point voltage fluctuation and to improve the voltage stability margin and the reactive power margin of the dynamic reactive power compensation equipment. The objective function is as follows:

$$
\min f_{2}=\omega_{1} \Delta Q_{S}+\omega_{2} \Delta U_{2}+\omega_{3} L_{p w}
$$

where $\Delta Q_{S}$ is the reactive power margin of SVC; $\Delta U_{2}$ is the voltage error of central point, and $L_{p w}$ is the static voltage stability index of power system. $\omega_{1}, \omega_{2}, \omega_{3}$ are the weighting factors. 


\subsection{Constraint Condition}

The proposed control strategy should meet the equality constraints and inequality constraints.

\subsubsection{Equality Constraints}

Equality constraints are mainly the power flow equations, which are as follows:

$$
\left\{\begin{array}{c}
P_{i-t}=U_{i-t} \sum_{j=1}^{N_{\mathrm{S}}} U_{j-t}\left(G_{i j} \cos \theta_{i j-t}+B_{i j} \sin \theta_{i j-t}\right) \\
Q_{i-t}=U_{i-t} \sum_{j=1}^{N_{\mathrm{S}}} U_{j-t}\left(G_{i j} \sin \theta_{i j-t}-B_{i j} \cos \theta_{i j-t}\right)
\end{array}\right.
$$

where, $i \in\left[1, N_{S}\right]$, and $N_{S}$ is the number of nodes, $P_{i-t}$ and $Q_{i-t}$ are the injected active and reactive power at time $t, G_{i j}, B_{i j}$, and $\theta_{i j-t}$ are the conductance, susceptance, and the phase displacement of the voltage between node $i$ and $j$, respectively.

\subsubsection{Inequality Constraints}

The inequality constraints of power system are mainly the constraints of state variables and control variables. The voltage should not exceed the limit. The formula is as follows:

$$
U_{i \min } \leq U_{i} \leq U_{i \max }
$$

Constraints of the control variables are mainly the reactive power output of the wind farm, $\mathrm{PV}$ power plant, and dynamic compensation equipment given in Equation (14).

$$
\left\{\begin{array}{c}
Q_{W \min } \leq Q_{W} \leq Q_{W \max } \\
Q_{P V \min } \leq Q_{P V} \leq Q_{P V \max } \\
K_{T \min } \leq K_{T} \leq K_{T \max } \\
Q_{C \min } \leq Q_{C} \leq Q_{C \max }
\end{array}\right.
$$

where $Q_{W}, Q_{P V}$, and $Q_{C}$ are the reactive power output of the wind farm, PV power station, and shunt capacitor. $K_{T}$ is the tap position of the transformer. $Q_{W \min }, Q_{P V \min }$, and $Q_{C \min }$ are the lower limits of the reactive power output of the wind farm, PV power station, and shunt capacitor. $Q_{W \max }, Q_{P V \max }$, and $Q_{C \max }$ are the upper limit of the reactive power output of the wind farm, PV power station, and shunt capacitor.

\section{Reactive Power Limit of the Wind Farm and PV Power Station}

The active and reactive power output of the DFIG is affected by the current limitation of the rotor winding, stator winding, and the converter of the rotor side. Among them, the current limit of the rotor-side converter is the main factor. The reactive power output limit of the stator side is given as follows:

$$
\left\{\begin{array}{c}
Q_{G \max }=-\frac{U_{s}^{2}}{X_{s}}+\sqrt{\left(\frac{X_{m}}{X_{s}} U_{s} i_{r \max }\right)^{2}-P_{s}^{2}} \\
Q_{G \min }=-\frac{U_{s}^{2}}{X_{s}}-\sqrt{\left(\frac{X_{m}}{X_{s}} U_{s} i_{r \max }\right)^{2}-P_{s}^{2}} \\
Q_{G \min } \leq Q_{G} \leq Q_{G \max }
\end{array},\right.
$$

where $U_{\mathrm{s}}$ is the terminal voltage of the stator side; $X_{m}$ is the excitation reactance; $X_{\mathrm{s}}$ is the stator reactance; $i_{r \max }$ is the upper current limit of the converter; $Q_{G \min }$ and $Q_{G \max }$ are the lower and upper limit of the reactive power output of the DFIG. 
The wind farm can be modelled differently according to the research focus. In this paper, the control strategy does not need to consider the internal electric connection and the differences among DFIGs. Therefore, the lumped model is chosen. The limit of reactive power output is given by Equation (16):

$$
\left\{\begin{array}{l}
Q_{W \min }=\sum_{i=1}^{n} Q_{G i \min } \\
Q_{W \max }=\sum_{i=1}^{n} Q_{G i \max }
\end{array}\right.
$$

where $Q_{G i m i n}$ and $Q_{G i m a x}$ are the lower limit and upper limit of reactive power output of the DFIG $i$. $Q_{W \min }$ and $Q_{W \max }$ are the lower limit and upper limit of the reactive power output of wind farm.

The reactive power output of the PV power station depends on the control strategy of the inverter. When the constant voltage control strategy is adopted, the active and reactive power output of the PV inverter needs to meet the constraint conditions given by Equation (17):

$$
P_{i p v}^{2}+Q_{i p v}^{2} \leq S_{i p v}^{2}
$$

where $P_{i p v}, Q_{i p v}$, and $S_{i p v}$ are the active power output, reactive power output and inverter capacity of the inverter. When reactive power loss of the power line, the transformer and the inverter are neglected, the limit of reactive power output of PV power station is given by Equation (18):

$$
Q_{p v \max }=\sum_{i=1}^{m} Q_{i p v \max }
$$

where $Q_{p v \max }$ is the reactive power upper limit of PV power plant; $Q_{i p v} \max$ is the upper limit of the reactive power output of inverter; $m$ is the number of inverters.

\section{Model Solution}

In this paper, the particle swarm optimization (PSO) algorithm is used to solve the two-tier reactive power and voltage control strategy [29]. Each particle includes the reactive power output of the capacitor bank, wind farm, photovoltaic power station, and SVC at time $t$. The flowchart within a control cycle is shown in Figure 2. The detailed process is as follows:

- $\quad$ STEP1: Initialize the size of PSO algorithm population $N$, the weight coefficient $\omega$ and so on;

- STEP2: Calculate the fitness value of each particle, and then, the individual optimal value $P_{\text {best }}$ and the global optimal value $G_{\text {best }}$ can be obtained;

- STEP3: Update the position and velocity of each particle;

- STEP4: Stop the search if the stop condition is satisfied; else, go to step 2; and

- STEP5: Check if the data is reasonable. If the data is reasonable, execute the control strategy; if not, calculate again. 


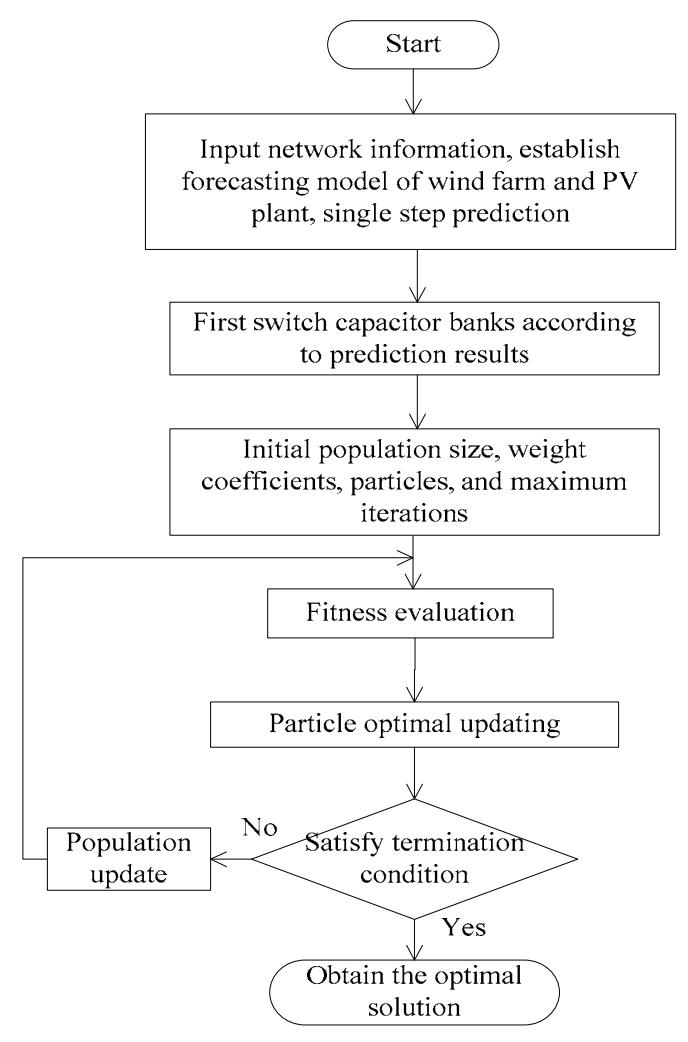

Figure 2. Flowchart of the two-tier reactive power and voltage control.

\section{Simulation Analysis}

\subsection{The Establishment of Time Series Model Based on ARMA}

Based on the output data gathered from wind farm and PV power station in Ningxia, the model is established through data processing, model determination, parameter estimation, and adequacy validation.

The parameters $p, q$ of the ARMA $(p, q)$ model can be determined by the autocorrelation function and partial correlation function of time series. In order to improve the feasibility of the model in the system, firstly, the data of the wind power and solar power are standardized. The autocorrelation and partial correlation of the data after standardization are given in Figure 3.

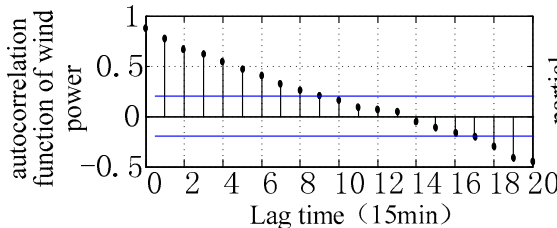

(a)

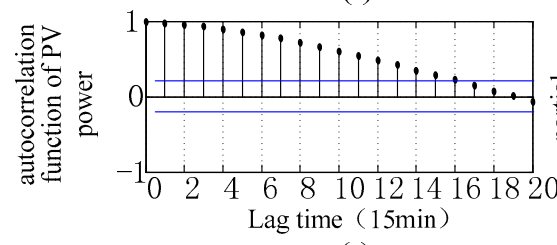

(c)

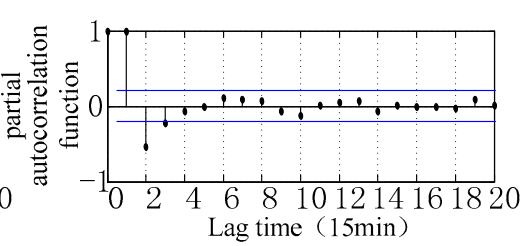

(b)

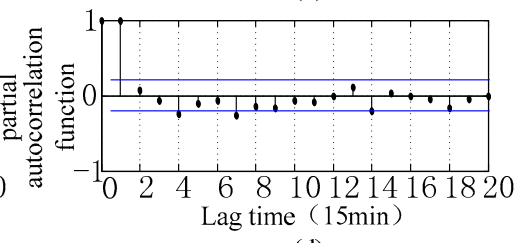

(d)

Figure 3. Autocorrelation function and partial autocorrelation function of the time series of output of the $(\mathbf{a}, \mathbf{b})$ wind farm and $(\mathbf{c}, \mathbf{d})$ solar power station. 
We can see from Figure 3 that the autocorrelation of the output of the wind farm and PV power station decay to smaller values after nine and 15 time lags, respectively (the resolution of the forecasting is $15 \mathrm{~min}$.). The partial correlation of the output of the wind farm and PV power station decay to a smaller value after two and one time lags, respectively. Therefore, the prediction model of the output of the wind farm and PV power plant should use the ARMA model, and the time series model of wind farm and PV power station are ARMA $(9,2)$ and ARMA $(15,1)$, respectively.

The parameters in Equation (3) of the model are estimated through MATLAB 2010b after the model is determined. The actual output curve and the forecasted output curve are shown in Figure 4 . As the output of the wind farm and PV power station has a strong randomness, there is usually a certain error between the predicted and actual values. Shown in Figure 4, for wind power prediction, the mean absolute error is $2.23 \mathrm{MW}$, and the mean relative error is $8.98 \%$. For PV power prediction, the mean absolute error is $1.16 \mathrm{MW}$, and the mean relative error is $7.46 \%$. The estimation errors of the ARMA model, most of the time, are precise enough for the pre-control with shunt capacitors.

Lastly, the residual sequence is obtained through the method of paper [27]. The residual sequence is the white noise sequence, so the model is in accordance with the requirements.

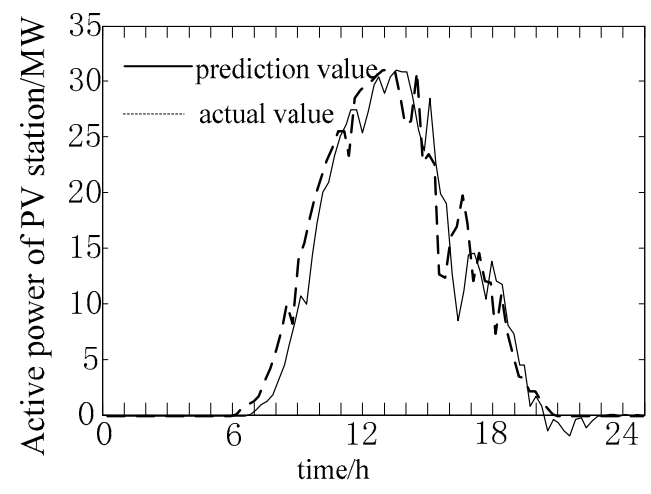

(a)

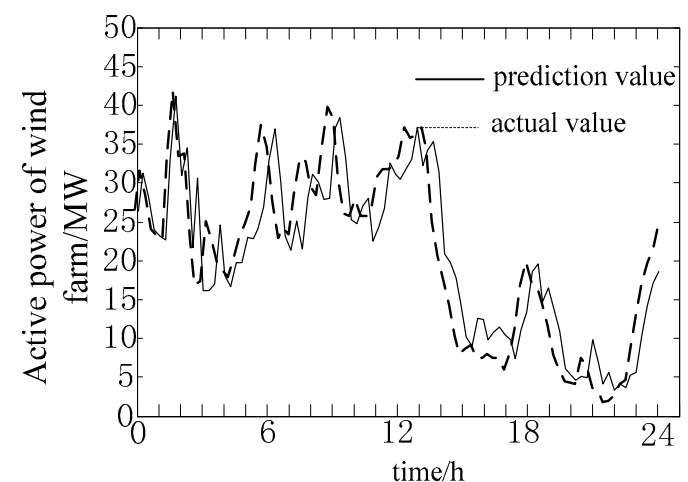

(b)

Figure 4. Curves of the actual value and prediction value of (a) PV power and (b) wind power.

\subsection{Test System}

The improved IEEE14 system with the integration of a wind farm and a PV station is used to verify the proposed method. The installed capacity of the wind farm is $49.5 \mathrm{MW}$, which is connected to node 14. At the booster station, five sets of shunt capacitors are installed and the capacity of each set is 1 MVar. A SVC of 5 MVar is installed. The installed capacity of the PV power station is $39.5 \mathrm{MW}$, which is connected to node 9 of the system. At the booster station, the reactive power compensation devices are the same as those in the wind farm.

In order to compare the effectiveness of the proposed strategy, two cases with different voltage control methods are constructed as follows:

- Method 1: No forecasting for the output of wind farm and PV power station. The objective function is to minimize of voltage deviation. The wind farm and PV power stations operate at unity power factor. The control cycle is $15 \mathrm{~min}$.

- Method 2: The control strategy proposed in this paper is applied. The power factor of wind farm and PV power station varies between -0.95 and 0.95 . The control cycle is $15 \mathrm{~min}$.

\subsection{Simulation Results}

$U_{\text {ref }}$ is set to be 1 . The output of the reactive power of the shunt capacitor is shown in Figure 5. The output of the reactive power of the SVC, wind farm, and PV power station are shown in Figure 6. 


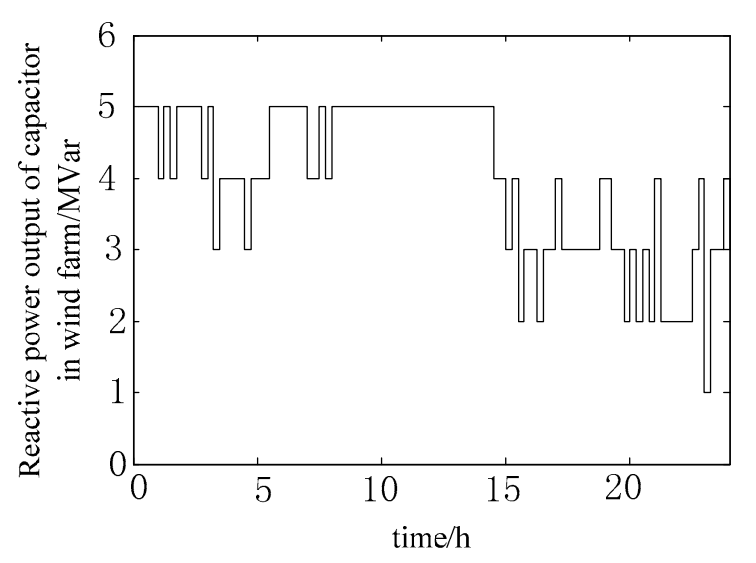

(a)

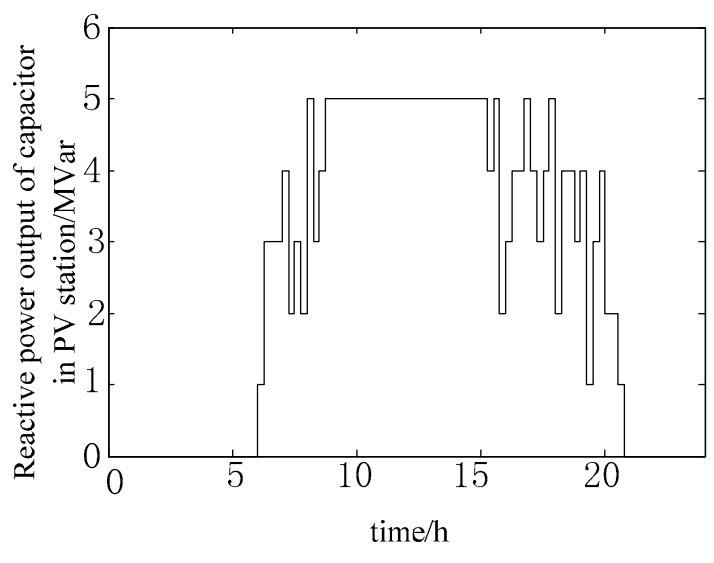

(b)

Figure 5. Reactive power output of the capacitor in (a) wind farm and (b) PV station.

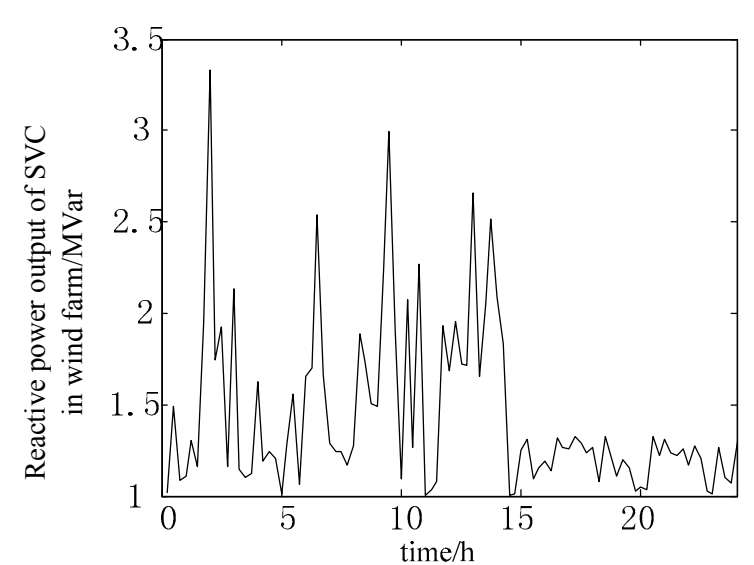

(a)

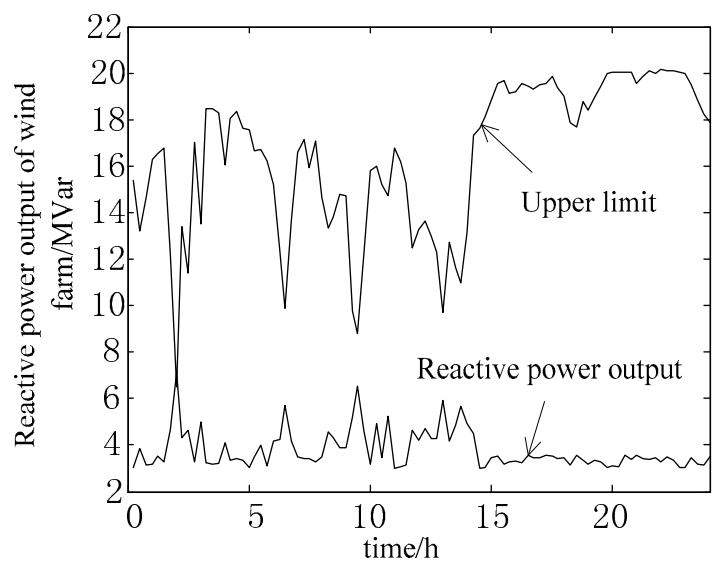

(c)

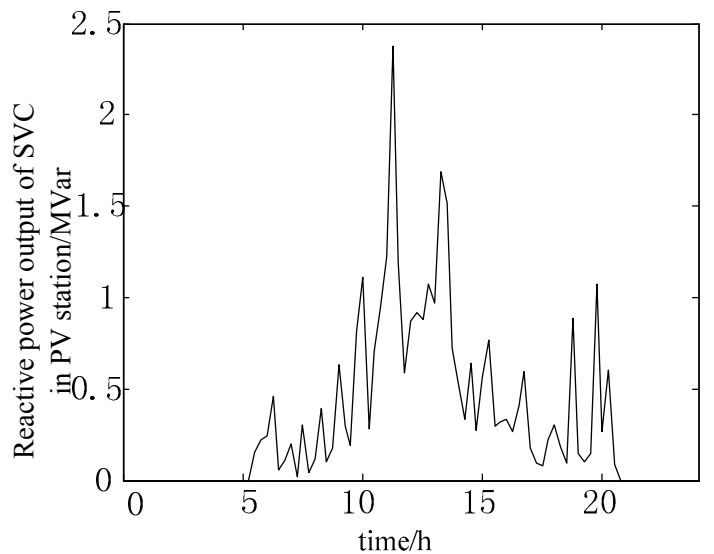

(b)

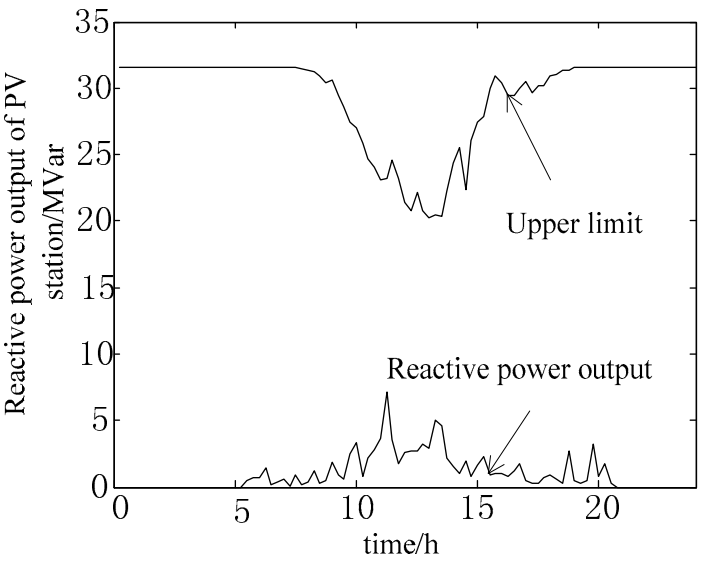

(d)

Figure 6. The reactive power output of the (a,b) SVC, (c) wind farm, and (d) PV plant.

From Figures 4 and 6, the upper limit of the reactive power output of the wind farm and PV power station varies with the change of the active power output. When the active power output of the wind farm is close to full power, the upper limit of the reactive power is small. However, more reactive power is needed at this time. When the reactive power of the wind farm and the capacitors are not enough to meet the demand of the reactive power, the dynamic compensation device needs to generate more reactive power. When the reactive power output of wind farm and PV power station 
meet the demand, the reactive power output of the SVC is less, and the reactive power margin of the SVC is high.

\subsection{Analysis of Voltage}

The curves of the voltage varying with the output of the active power of the wind farm and PV plant are shown in Figure 7. The variation of the index of the voltage stability margin is shown in Figure 8.

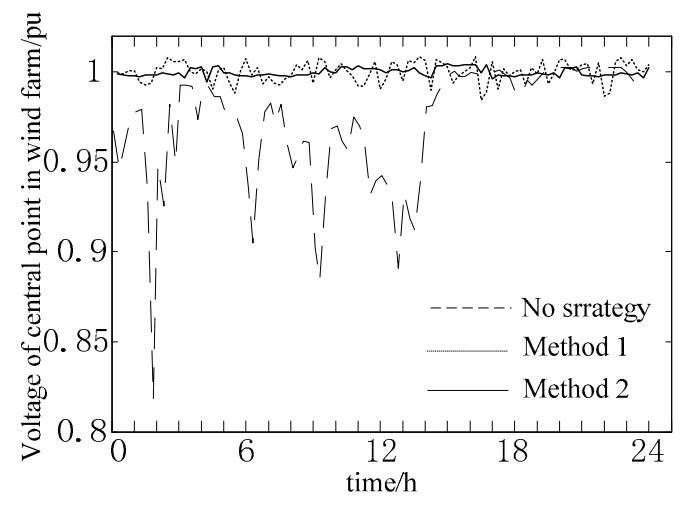

(a)

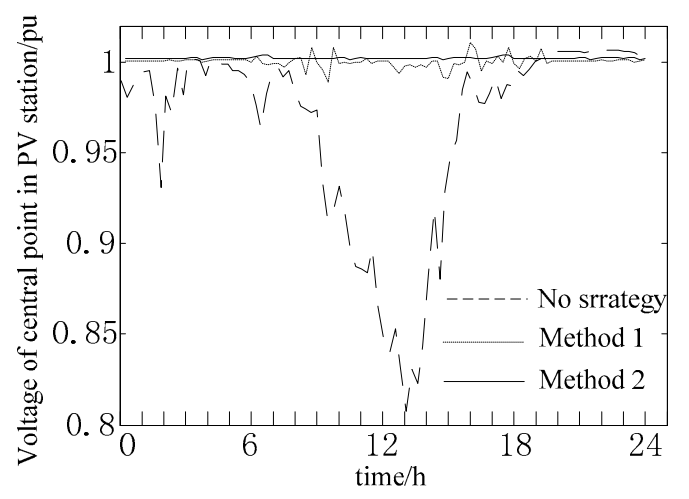

(b)

Figure 7. Voltage curves of the central point in (a) wind farm and (b) PV station.

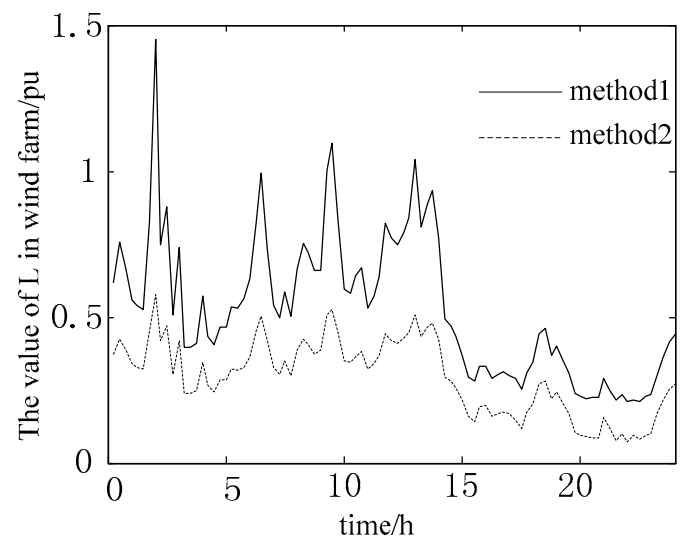

(a)

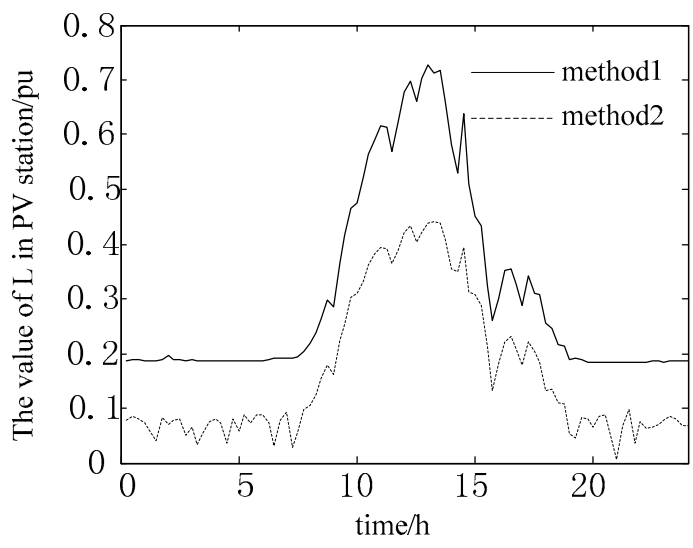

(b)

Figure 8. The L-index values for the PCC of the (a) wind farm and (b) PV plant.

As we can see from Figure 7, when reactive power control strategy is not used, the voltage exceeds the lower limit and fluctuates significantly, which does not meet the voltage level. Methods 1 and 2 can both suppress the fluctuation of voltage. However, method 1 ignores the predicted information, and the voltage fluctuates more significantly than that controlled by method 2. Additionally, as we can see from Figure 8, the voltage stability margin is larger by method 2 than by method 1 . Thus, the proposed method (method 2) can suppress the fluctuation of voltage and improve the static voltage stability.

\section{Conclusions}

A two-tier reactive power and voltage control strategy based on the ARMA model for a power grid with a wind farm and PV plant is proposed, considering the static voltage stability margin and regulating characteristic between the different reactive power compensation devices. Based on single-step prediction information, discrete equipment are regulated prior to other devices, aiming at 
minimizing the voltage deviation at the center point. The dynamic VAR compensation devices, the reactive power output of the wind farm, and the PV plant are then controlled in a coordinated manner in order to minimize the voltage deviation at the central point, maximize the voltage stability margin, and maximize the reactive power margin. Through the simulation analysis, the following conclusions can be drawn:

- The proposed control strategy can improve the reactive power margin of dynamic devices and suppress the voltage fluctuation; and

- The proposed control strategy can improve the system voltage stability margin and the voltage stability, as well.

Acknowledgments: This work was supported partially by the National Natural Science Foundation of China (Grant No. 51577067), the Beijing Natural Science Foundation of China (Grant No. 3162033), the Hebei Natural Science Foundation of China (Grant No. E2015502060), the State Key Laboratory of Alternate Electrical Power System with Renewable Energy Sources (Grant Nos. LAPS16007, LAPS16015), the Science and Technology Project of State Grid Corporation of China (SGCC), the Open Fund of State Key Laboratory of Operation and Control of Renewable Energy \& Storage Systems (China Electric Power Research Institute) (No. 5242001600FB) and the China Scholarship Council. M. Shafie-khah and J.P.S. Catalão acknowledge the support by FEDER funds through COMPETE 2020 and by Portuguese funds through FCT, under Projects SAICT-PAC/0004/2015-POCI-01-0145-FEDER-016434, POCI-01-0145-FEDER-006961, UID/EEA/50014/2013, UID/CEC/50021/2013, and UID/EMS/00151/2013, and also funding from the EU 7th Framework Programme FP7/2007-2013 under GA No. 309048.

Author Contributions: All authors have worked on this manuscript together and all authors have read and approved the final manuscript.

Conflicts of Interest: The authors declare that the grant, scholarship, and/or funding mentioned in the Acknowledgments section do not lead to any conflict of interest. Additionally, the authors declare that there is no conflict of interest regarding the publication of this manuscript.

\section{References}

1. Reddy, S.S.; Momoh, J.A. Realistic and transparent optimum scheduling strategy for hybrid power system. IEEE Trans. Smart Grid 2015, 6, 3114-3125. [CrossRef]

2. Chakraborty, S.; Ito, T.; Senjyu, T.; Saber, A.Y. Intelligent economic operation of smart-grid facilitating fuzzy advanced quantum evolutionary method. IEEE Trans. Sustain. Energy 2016, 78, 239-247. [CrossRef]

3. Castro, J.R.; Saad, M.; Lefebvre, S.; Asber, D.; Lenoir, L. Optimal voltage control in distribution network in the presence of DGs. Int. J. Electr. Power Energy Syst. 2013, 4, 905-916. [CrossRef]

4. Boemer, J.C.; Gibescu, M.; Kling, W.L. Dynamic models for transient stability analysis of transmission and distribution systems with distributed generation: An overview. In Proceedings of the 2009 IEEE Bucharest, PowerTech, Bucharest, Romania, 28 June-2 July 2009.

5. Cai, G.; Kong, L.; Chao, P.; Yang, D.; Sun, Z.; University, N.D. System modeling of Wind-PV-ES hybrid power system and its control strategy for grid-connected. Trans. China Electrotech. Soc. 2013, 28, 196-204.

6. Mohseni, M. Enhanced reactive power support capability of fully rated converter-based wind generators. In Proceedings of the 37th Annual Conference on IEEE Industrial Electronics Society, Melbourne, Australia, 7-10 November 2011.

7. Kayikci, M.; Milanovic, J.V. Reactive power control strategies for DFIG-based plants. IEEE Trans. Energy Convers. 2007, 22, 389-396.

8. Song, W.; Li, G.; Ming, Z. The reactive power adjusting mechanism \& control strategy of doubly fed induction generator. Proc. CSEE 2014, 16, 2714-2720.

9. Martínez, J.; Kjær, P.C.; Rodriguez, P.; Teodorescu, R. Design and analysis of a slope voltage control for a DFIG wind power plant. IEEE Trans. Energy Convers. 2012, 27, 11-20. [CrossRef]

10. Ou, R.; Xiao, X.Y.; Zou, Z.C.; Zhang, Y.; Wang, Y.H. Cooperative control of SFCL and reactive power for improving the transient voltage stability of grid-connected wind farm with DFIGs. IEEE Trans. Appl. Supercond. 2016, 26, 1-6. [CrossRef]

11. Sharma, P.; Thukaram, D. Reactive power and voltage control in grid connected wind farms. In Proceedings of the IEEE International Conference on Industrial and Information Systems, Chennai, India, 6-9 August 2012. 
12. Kumar, V.S.S.; Reddy, K.K.; Thukaram, D. Coordination of reactive power in grid-connected wind farms for voltage stability enhancement. IEEE Trans. Power Syst. 2014, 29, 2381-2390. [CrossRef]

13. Ahmidi, A.; Guillaud, X.; Besanger, Y.; Blanc, R. A multilevel approach for optimal participating of wind farms at reactive power balancing in transmission power system. IEEE Syst. J. 2012, 6, 260-269. [CrossRef]

14. Liu, X.; Wang, H.; Sun, H. Area automatic voltage control of large-scale wind farms. In Proceedings of the Power and Energy Engineering Conference, Shanghai, China, 27-29 March 2012.

15. Ghasemi, M.A.; Parniani, M. Prevention of distribution network overvoltage by adaptive droop-based active and reactive power control of PV systems. Electr. Power Syst. Res. 2016, 133, 313-327. [CrossRef]

16. Liu, X.; Cramer, A.M.; Liao, Y. Reactive power control methods for photovoltaic inverters to mitigate short-term voltage magnitude fluctuations. Electr. Power Syst. Res. 2015, 127, 213-220. [CrossRef]

17. Kang, Q.; Xu, W.; Sun, C.; Zhao, J.; Fu, Z.; Yue, Y. Reactive power control strategy of grid-connection for the Wind-PV hybrid system. Proc. CSU-EPSA 2014, 1, 28-33.

18. Wang, F.; Xu, H.; Xu, T.; Li, K.; Shafie-Khah, M.; Catalao, J.P.S. The values of market-based demand response on improving power system reliability under extreme circumstances. Appl. Energy 2017, 193, 220-231. [CrossRef]

19. Catalao, J.P.S.; Pousinho, H.M.I.; Mendes, V.M.F. Hybrid Wavelet-PSO-ANFIS approach for short-term wind power forecasting in portugal. IEEE Trans. Sustain. Energy 2011, 2, 50-59.

20. Wan, C.; Xu, Z.; Pinson, P. Direct interval forecasting of wind power. IEEE Trans. Power Syst. 2013, 28, 4877-4878. [CrossRef]

21. Erdem, E.; Shi, J. ARMA based approaches for forecasting the tuple of wind speed and direction. Appl. Energy 2011, 88, 1405-1414. [CrossRef]

22. Catalao, J.P.S.; Pousinho, H.M.I.; Mendes, V.M.F. Short-term wind power forecasting in Portugal by neural networks and wavelet transform. IET Renew. Power Gener. 2011, 36, 1245-1251. [CrossRef]

23. Wan, C.; Song, Y.; Xu, Z.; Yang, G.; Nielsen, A.H. Probabilistic wind power forecasting with hybrid artificial neural networks. IEEE Power Eng. Rev. 2016, 44, 1656-1668. [CrossRef]

24. Wang, F.; Mi, Z.; Su, S.; Zhao, H. Short-term solar irradiance forecasting model based on artificial neural network using statistical feature parameters. Energies 2012, 5, 1355-1370. [CrossRef]

25. Wang, F.; Zhao, Z.; Mi, Z.; Sun, H.; Shi, S.; Yang, G. Solar irradiance feature extraction and support vector machines based weather status pattern recognition model for short-term PV power forecasting. Energy Build. 2015, 86, 427-438. [CrossRef]

26. Sun, Y.; Wang, F.; Wang, B.; Chen, Q.; Engerer, N.A.; Mi, Z. Correlation feature selection and mutual information theory based quantitative research on meteorological impact factors of module temperature for solar photovoltaic systems. Energies 2016, 10, 7. [CrossRef]

27. Wang, J. Study on Forecasting the Wind Speed and Wind Power Based on the Measured Data of a Wind Farm; Northeast Dianli University: Jilin, China, 2010.

28. Shuo, Y.; Wang, W.; Chun, L.; Huang, Y. Coordinative strategy of reactive power and voltage control for improving static voltage stability of wind power centralized system. Power Syst. Technol. 2014, 38, 1250-1256.

29. Yuan, X.; Cheng, W.; Zhang, Y.; Yuan, Y. A survey on application of particle swarm optimization to electric power systems. Power Syst. Technol. 2004, 28, 14-19.

(C) 2017 by the authors. Licensee MDPI, Basel, Switzerland. This article is an open access article distributed under the terms and conditions of the Creative Commons Attribution (CC BY) license (http://creativecommons.org/licenses/by/4.0/). 